\title{
Morfometria corpórea, características do sêmen, proteínas seminais e testosterona em cervos Cervus unicolor, em cativeiro
}

\author{
[Body morphometry, semen characteristics, seminal proteins and \\ testosterone in sambar deer (Cervus unicolor) in captivity] \\ M.G.M. Chacur $^{1}$, E.A.F. Martins ${ }^{2}$, A.A. Silva ${ }^{2}$, L.M. Guaberto ${ }^{1}$, \\ L.R.A. Gabriel Filho ${ }^{3}$, O.C. Sanches ${ }^{1}$, E. $\mathrm{Oba}^{4}$ \\ ${ }^{1}$ Universidade do Oeste Paulista - Unoeste - Presidente Prudente, SP \\ ${ }^{2}$ Aluno de pós-graduação - Unoeste - Presidente Prudente, SP \\ ${ }^{3}$ Unesp, Tupã, SP \\ ${ }^{4}$ FMVZ-Unesp, Botucatu, SP
}

\begin{abstract}
RESUMO
Objetivou-se estudar a morfometria corpórea, as características do sêmen, o perfil proteico do plasma seminal em SDS-PAGE e a concentração sérica de testosterona em cervos-sambar (Cervus unicolor), criados em cativeiro, na estação reprodutiva da primavera. Quatro machos com idades entre 12 e 36 meses foram avaliados em quatro momentos, com intervalos de sete dias, com peso corpóreo (60,5 a $89,0 \mathrm{~kg})$, índice de massa corporal $\left(93,07 \mathrm{~kg} / \mathrm{m}^{2}\right.$ a $\left.\mathbf{1 2 6}, 56 \mathrm{~kg} / \mathrm{m}^{2}\right)$, volume do ejaculado $(0,50 \pm 0,35 \mathrm{~mL}$ a $0,75 \pm 0,28 \mathrm{~mL})$, motilidade espermática $(87,75 \pm 4,78 \%$ a $90,00 \pm 7,07 \%)$, defeitos totais $(17,25 \pm 5,81 \%$ a $47,72 \pm 17,55 \%)$, testosterona sérica $(6,43 \pm 4,33 \mathrm{ng} / \mathrm{dL}$ a $166,00 \pm 64,48 \mathrm{ng} / \mathrm{dL})$ e proteínas do plasma seminal com bandas entre 7,6 e 142kDa. As características dos ejaculados não diferiram $(\mathrm{P}>0,05)$ entre as três primeiras colheitas. Houve diferença $(\mathrm{P}<0,05)$ para os defeitos espermáticos com elevação na quarta colheita. No plasma seminal de cada cervo, foram identificadas de 16 a 27 bandas de proteínas entre 7,6 e $142 \mathrm{kDa}$. Conclui-se que a qualidade espermática foi satisfatória na primavera. O estresse das contenções sucessivas causou queda da qualidade espermática. A idade influi na concentração sérica de testosterona, a qual foi maior nos cervos aos 36 meses.
\end{abstract}

Palavras-chave: Cervidae, cativeiro, sêmen, SDS-PAGE, andrógeno

\begin{abstract}
The aim of this work was to study the body morphometry, semen characteristics, seminal plasma protein profile in SDS-PAGE and serum testosterone concentration in Sambar Deer (Cervus unicolor), in captivity in the breeding season (spring). Four males aged between 12 and 36 months were assessed in four moments with intervals of seven days with body weight (60.5 to 89.0kg), body mass index (93.07 to $\left.126.56 \mathrm{~kg} / \mathrm{m}^{2}\right)$, ejaculate volume $(0.50 \pm 0.35 \mathrm{~mL}$ to $0.75 \pm 0.28 \mathrm{~mL})$, sperm motility $(87.75 \pm 4.78 \%$ to $90.00 \pm 7.07 \%)$, total defects $(17.25 \pm 5.81 \%$ to $47.72 \pm 17.55 \%)$, serum testosterone $(6.43 \pm 4.33 \mathrm{ng} / \mathrm{dL}$ to $166.00 \pm 64.48 \mathrm{ng} / \mathrm{dL}$ ) and seminal plasma proteins with bands between 7.6 and $142 \mathrm{kDa}$. The characteristics of ejaculates did not differ $(P>0.05)$ among ejaculates $\left(1^{\text {st }}, 2^{\text {nd }}\right.$ and $\left.3^{\text {rd }}\right)$. There were differences $(P<0.05)$ for sperm defects elevation on the fourth ejaculate. In seminal plasma 16 to 27 protein bands between 7.6 and $142 \mathrm{kDa}$ were identified. In conclusion, sperm quality was satisfactory in the spring and the stress of successive contentions decreased sperm quality. Also, there is influence of age upon serum testosterone concentration which was higher in deer at 36 months.
\end{abstract}

Keywords: Cervidae, captivity, semen, SDS-PAGE, androgen

Recebido em 24 de junho de 2013

Aceito em 22 de abril de 2014

E-mail: chacur@unoeste.br 


\section{INTRODUÇÃO}

A família Cervídae, da qual fazem parte os veados, pertence à ordem Artiodactyla. São os ruminantes selvagens mais disseminados no mundo (Van Soest, 1994), de cuja família faz parte o Cervus unicolor, conhecido como cervosambar.

O exame andrológico, uma das técnicas mais utilizadas para estimar a fertilidade, caracterizase por exame clínico, medida de circunferência escrotal e avaliação do espermatozoide para motilidade, vigor, turbilhonamento, concentração e morfologia (Salvador et al., 2002). As avaliações clínicas e seminais são fundamentais para classificação e prognóstico da função reprodutiva (Vale Filho et al., 1986).

A biologia molecular na área da reprodução animal traz ferramentas para o melhoramento genético, por meio da utilização de marcadores bioquímicos em fluidos orgânicos que demonstram o potencial genético de um animal, cuja seleção de genótipos superiores para determinadas características reprodutivas possa ser incrementada (Roncoletta et al., 1999).

O plasma seminal serve como veículo para os espermatozoides ejaculados e consiste em uma mistura de secreções dos testículos e das glândulas sexuais acessórias, com função carreadora dos gametas masculinos até o trato genital feminino a fim de viabilizar a fertilização (Manjunath, 1987; Einspanier, 1991). Os perfis eletroforéticos das proteínas do plasma seminal auxiliam na avaliação clínica, em casos de infertilidade (Gasset, 1997).

Relações têm sido demonstradas entre a concentração sanguínea de testosterona, a fertilidade e a motilidade espermática (Blockey e Galloway, 1978). As características fisiológicas reprodutivas podem sofrer alterações devido ao estresse em cativeiro (Pocay et al., 2001).

Devido à escassez de dados na literatura nacional, pouco se sabe sobre a esfera reprodutiva em cervos exóticos mantidos em cativeiro, como o Cervus unicolor. Dessa forma, o presente estudo justifica-se, pois informações obtidas de animais mantidos em cativeiro podem ser úteis para se traçar estratégias de manejo reprodutivo. Objetivou-se estudar a morfometria corpórea, o quadro espermático, as proteínas do plasma seminal em SDS-PAGE e a concentração sérica de testosterona em cervos-sambar criados em cativeiro na estação reprodutiva da primavera.

\section{MATERIAL E MÉTODOS}

Utilizaram-se quatro cervos-sambar, Cervus unicolor, machos, criados em cativeiro pertencente ao zoológico de Presidente Prudente - SP, com latitude de $21^{\circ} 29^{\prime} 50$ 'S; longitude de $49^{\circ} 14$ '2"W e altitude de $475 \mathrm{~m}$. Os cervos foram identificados com as letras: A, B, C e D, tendo os animais " $A$ " e " $B$ " idade de 36 meses e peso corpóreo de 89 e $95 \mathrm{~kg}$, respectivamente, o cervo "C" idade de 18 meses e peso de $81 \mathrm{~kg}$, e o animal " $D$ " idade de12 meses e peso de $60,5 \mathrm{~kg}$.

Os animais recebiam alimentação composta por frutas e legumes em proporções iguais: laranja, maçã, banana, mamão, beterraba, cenoura e abóbora, além de sal mineral, ração para bovinos (18\% proteína), capim-colonião Panicum maximum e água ad libitum. $\mathrm{O}$ experimento foi realizado no mês de novembro (primavera), e os fatores climáticos aferidos na estação foram: temperatura ambiente média $\left(24,5^{\circ} \mathrm{C}\right)$, insolação (239,74h), índice pluviométrico cumulativo (126mm) e umidade relativa do ar $(80,6 \%)$. O clima é caracterizado pela presença de massas de ar tropicais e polares, com estação de inverno fria e seca, e verão quente e chuvoso.

Anteriormente às mensurações corpóreas e às colheitas de sangue e sêmen, foi realizada sedação com zolazepam e tiletamina (Zoletil®) associados à xilazina (Rompun $\left.{ }^{\circledR}\right)$.

Os cervos foram pesados, e a altura da cernelha mensurada para a obtenção do índice de massa corpórea (IMC), sendo IMC = peso corpóreo $(\mathrm{kg}) /(\text { altura da cernelha em metros })^{2}$. Foram realizadas quatro colheitas de sêmen por animal, com intervalo de sete dias, por meio de eletroejaculador automático (Autoejac $®$, Neovet, Brasil) com probe retal para ovinos, com estímulos elétricos de dois a três segundos, seguidos por igual tempo de repouso. As amostras de sêmen foram analisadas com relação às características quantitativas e qualitativas: volume $(\mathrm{mL})$, cor, aspecto, motilidade espermática (\%), vigor espermático (1 a 5), turbilhonamento (1 a 5), concentração 
espermática $\left(\times 10^{6} / \mathrm{mL}\right)$, defeitos espermáticos maiores, menores e totais (\%). Posteriormente, os ejaculados foram centrifugados a $1500 \mathrm{~g} / 15 \mathrm{~min}$. Separou-se e estocou-se $1 \mathrm{~mL}$ de plasma seminal a $-20^{\circ} \mathrm{C}$ para posterior realização da técnica de eletroforese em SDS-PAGE.

A eletroforese em SDS-PAGE foi processada com extrações das proteínas segundo Laemilli (1970) e quantificações conforme Bradford (1976) com espectrofotômetro (PF-901 Chemistry Analyser Labsystems, USA). A extração das proteínas foi realizada utilizando-se tampão composto por: buffer A - TRIS HCl $(6,0 \mathrm{~mL}) \mathrm{pH} 6,8(4,0 \mathrm{~mL})$, glicerol $(6,4 \mathrm{~mL})$, SDS $10 \%(6,4 \mathrm{~mL})$, mercaptoetanol $(1,6 \mathrm{~mL})$ e água destilada (13,6mL). Empregou-se a relação 2:1, diluindo-se em tubo de ensaio $200 \mu \mathrm{L}$ de amostra e $1000 \mu \mathrm{L}$ do tampão de extração para cada amostra, mantidos por três minutos em ebulição. Logo após, as proteínas foram quantificadas em espectrofotômetro com solução contendo: Bradford (4,5mL), $\mathrm{NaCl} 0,15 \mathrm{M} \quad(0,45 \mathrm{~mL})$ e amostra de proteína $(0,05 \mathrm{~mL})$. As amostras foram aplicadas em cuba de eletroforese vertical $20 \times 20 \mathrm{~cm}$ (Omniphor $\left.{ }^{\circledR}\right)$ ligada a $(50 \mathrm{~V} \times 50 \mathrm{Ma} / 30$ min; e $300 \mathrm{Vx} 16 \mathrm{~mA} / 4$ a $6 \mathrm{~h}$ ) uma fonte elétrica de 0 a 1000W (PWSYS EI®). A revelação das bandas proteicas foi feita em solução a $2 \%$ de Comassie Brilliant Blue G-250, com captura, visualização e processamento das imagens em transluminador (Doc-IT-LS ${ }^{\circ} \quad 6.0$ software, USA).

Concomitantemente às colheitas de sêmen, foram realizadas as colheitas de sangue por venopunção jugular, quatro colheitas por cervo, realizadas entre oito e nove e meia da manhã, em um totalizando 16 amostras, seguida por centrifugação a $1500 \mathrm{~g} / 15 \mathrm{~min}$, para separação do soro sanguíneo, o qual foi estocado a $-20^{\circ} \mathrm{C}$ para posterior dosagem de testosterona (ng/dL) pelo método de radioimunoensaio (RIA), utilizandose kit comercial para testosterona total (DPC Coat a Count ${ }$ - MedLab).

Após a quarta e última colheita de sêmen e sangue, foram feitas biópsias dos testículos com auxílio de agulha modelo Tru-Cut (16G) para biópsia. Os fragmentos foram fixados em solução de Davidson por 24 horas e, em seguida, foram lavados em água corrente por 20 minutos e transferidos para solução alcoólica $70^{\circ} \mathrm{GL}$. Posteriormente, foram processados conforme técnica para microscopia óptica e inclusão em parafina. Os cortes foram corados pela técnica da hematoxilina-eosina (HE). Para o processamento estatístico dos dados do sêmen, foi empregada a análise de variância, e, para a comparação das médias, aplicou-se o teste Tukey a $5 \%$.

O presente projeto de pesquisa foi aprovado pelo Comitê de Ética e Uso de Animais para Experimentação (CEUA) da Universidade do Oeste Paulista - Unoeste, protocolo 299/2010.

\section{RESULTADOS E DISCUSSÃO}

O estudo da morfometria corpórea se faz importante para se conhecer o porte dos animais, relacionando-o com o índice de massa corpórea (IMC), variável utilizada para estimar a aptidão física do animal em conjunto com as variáveis reprodutivas (Chacur et al., 2010). As médias das características morfométricas dos cervos utilizados no experimento estão apresentadas na Tab. 1.

Tabela 1. Média da idade e das características morfométricas: peso corpóreo, comprimento craniocaudal, altura de cernelha, índice de massa corpórea (IMC) e diâmetro torácico em cervos, Cervus unicolor, mantidos em cativeiro

\begin{tabular}{lcccc}
\hline \multirow{2}{*}{ Parâmetros } & \multicolumn{4}{c}{ Cervos } \\
\cline { 2 - 5 } & $\mathrm{A}$ & $\mathrm{B}$ & $\mathrm{C}$ & $\mathrm{D}$ \\
\hline Idade (meses) & 36 & 36 & 18 & 12 \\
Peso $(\mathrm{kg})$ & 89,0 & 95,0 & 81,0 & 60,5 \\
Comprimento (m) & 1,39 & 1,43 & 1,26 & 1,24 \\
Altura da cernelha (m) & 0,92 & 0,89 & 0,80 & 0,81 \\
IMC $\left(\mathrm{kg} / \mathrm{m}^{2}\right)$ & 105,95 & 120,25 & 126,56 & 93,07 \\
Diâmetro torácico (m) & 1,01 & 1,09 & 0,88 & 0,87 \\
\hline
\end{tabular}


Com relação às características quantitativas e qualitativas do sêmen, não houve diferenças $(\mathrm{P}>0,05)$ entre os quatro momentos de colheita, exceto na morfologia espermática da quarta colheita, para os defeitos maiores, menores e totais com elevação das porcentagens de defeitos morfológicos em relação às três primeiras colheitas (Tab. 2). Vale destacar que o método de colheita de sêmen por eletroejaculação mostrouse de fácil execução para a obtenção dos ejaculados.

A necessidade da contenção química por sedação anestésica propiciou uma colheita de sêmen rápida, pois reduziu o estresse do procedimento. A literatura destaca que o estresse das condições do cativeiro é causado pelo aprisionamento, pela redução da liberdade e pela imposição da convivência constante com vários indivíduos, quando, na natureza, esses animais vivem isolados a maior parte do tempo (Duarte e Merino, 1997). Em concordância com o raciocínio do estresse do cativeiro e dos fatores estressantes associados, uma alta porcentagem de defeitos totais $(40,9 \pm 10,42 \%)$ foi relatada em cervos no Brasil (Abreu et al., 2009).

Com relação à morfologia espermática, os valores médios obtidos para os defeitos espermáticos maiores (cabeça isolada patológica, cabeça pequena anormal, gota citoplasmática proximal, defeitos de peça intermediária, cauda fortemente dobrada ou enrolada e enrolada na cabeça), menores (cabeça isolada normal, retroaxial, abaxial, dobrada ou enrolada e gota citoplasmática distal) e defeitos espermáticos totais das três primeiras colheitas foram semelhantes aos descritos por Cheng et al. (2004).

Tabela 2. Média das características quantitativas e qualitativas das colheitas de sêmen de cervos, Cervus unicolor, mantidos em cativeiro

\begin{tabular}{lcccc}
\hline \multirow{2}{*}{ Variáveis } & \multicolumn{4}{c}{ Colheitas } \\
\cline { 2 - 5 } & $0,75 \pm 0,28 \mathrm{~A}$ & $0,75 \pm 0,28 \mathrm{~A}$ & $0,50 \pm 0,35 \mathrm{~A}$ & $0,62 \pm 0,25 \mathrm{~A}$ \\
\hline Volume (mL) & $1,75 \pm 0,95 \mathrm{~A}$ & $1,50 \pm 1,00 \mathrm{~A}$ & $1,25 \pm 0,50 \mathrm{~A}$ & $1,25 \pm 0,50 \mathrm{~A}$ \\
Cor & $1,75 \pm 0,95 \mathrm{~A}$ & $1,75 \pm 0,50 \mathrm{~A}$ & $1,25 \pm 0,50 \mathrm{~A}$ & $1,25 \pm 0,50 \mathrm{~A}$ \\
Aspecto & $87,50 \pm 5,00 \mathrm{~A}$ & $83,75 \pm 4,78 \mathrm{~A}$ & $90,00 \pm 7,07 \mathrm{~A}$ & $83,75 \pm 4,78 \mathrm{~A}$ \\
Motilidade $(\%)$ & $5,00 \pm 0,00 \mathrm{~A}$ & $5,00 \pm 0,00 \mathrm{~A}$ & $4,75 \pm 0,25 \mathrm{~A}$ & $4,75 \pm 0,25 \mathrm{~A}$ \\
Vigor $(1-5)$ & $4,00 \pm 1,00 \mathrm{~A}$ & $4,00 \pm 1,00 \mathrm{~A}$ & $4,00 \pm 1,00 \mathrm{~A}$ & $4,00 \pm 1,00 \mathrm{~A}$ \\
Turbilhão $(1-5)$ & $1137,5 \pm 892,5 \mathrm{~A}$ & $1144,1 \pm 557,6 \mathrm{~A}$ & $1140,6 \pm 699,6 \mathrm{~A}$ & $1027 \pm 763,6 \mathrm{~A}$ \\
Concentração & & & & \\
(x10\%mL) & $7,36 \pm 4,25 \mathrm{~A}$ & $5,79 \pm 2,19 \mathrm{~A}$ & $9,62 \pm 3,93 \mathrm{~A}$ & $17,00 \pm 1,87 \mathrm{~B}$ \\
Defeitos maiores $(\%)$ & $10,51 \pm 3,82 \mathrm{~A}$ & $11,45 \pm 6,50 \mathrm{~A}$ & $10,78 \pm 2,79 \mathrm{~A}$ & $25,85 \pm 15,05 \mathrm{~B}$ \\
Defeitos menores $(\%)$ & $18,35 \pm 13,93 \mathrm{~A}$ & $17,25 \pm 5,81 \mathrm{~A}$ & $20,41 \pm 2,74 \mathrm{~A}$ & $47,72 \pm 17,55 \mathrm{~B}$ \\
Defeitos totais $(\%)$ & & & & \\
\hline
\end{tabular}

Letras diferentes (A, B) na linha ( $\mathrm{P}<0,05)$; cor: (1) amarelo, (2) branco, (3) branco marmóreo; aspecto:

(1) cremoso, (2) leitoso, (3) aquoso.

A elevação da porcentagem de defeitos espermáticos obtida na quarta colheita (Tab. 2) pode estar associada ao estresse cumulativo e às contenções semanais para as colheitas de sangue e sêmen. Os defeitos espermáticos maiores se elevaram nos quatro animais ao longo das colheitas de sêmen (Tab. 3).

No presente estudo, o volume dos ejaculados foi semelhante ao observado em machos sexualmente maduros Formosan Sika deer e
Formosan Sambar deer, com 0,5 $\pm 0,4 \mathrm{~mL}$ (Cheng et al., 2004), e diferiu do relatado por Abreu et

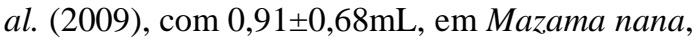
e por Ascher et al. (2000), com volume de $1,5 \pm 0,6 \mathrm{~mL}$ em cervos Dama dama. O volume dos ejaculados pode variar conforme a espécie, a idade, o peso, a frequência de ejaculação e o tamanho do aparelho reprodutor dos cervos (Ascher et al., 2000; Cheng et al., 2004; Abreu et al., 2009). 
Tabela 3. Porcentagens de defeitos espermáticos maiores, defeitos menores e defeitos totais nas quatro colheitas de sêmen em cervos, Cervus unicolor, mantidos em cativeiro

\begin{tabular}{ccccc}
\hline Cervo & Colheita & Defeitos maiores & Defeitos menores & Defeitos totais \\
\hline A & 1 & 5,46 & 6,72 & 12,18 \\
& 2 & 5,5 & 6,5 & 12 \\
& 3 & 6,22 & 3,82 & 10,04 \\
& 4 & 14,21 & 25 & 39,21 \\
B & 1 & 3,27 & 19,62 & 22,89 \\
& 2 & 4,67 & 5,6 & 10,27 \\
& 3 & 7,88 & 6,89 & 14,77 \\
& 4 & 7,35 & 13,72 & 21,07 \\
C & 1 & 4,48 & 12,55 & 17,03 \\
& 2 & 14,07 & 7,28 & 21,35 \\
& 3 & 9,86 & 9,86 & 19,72 \\
& 4 & 10,09 & 13,46 & 23,55 \\
$\mathrm{D}$ & 1 & 16,25 & 14,77 & 31,02 \\
& 2 & 16,98 & 14,62 & 31,06 \\
& 3 & 15,19 & 27,45 & 42,64 \\
& 4 & 19,6 & 46,56 & 66,16 \\
\hline
\end{tabular}

As motilidades médias obtidas no presente estudo (Tab. 2) foram superiores às descritas por Cheng et al. (2004), com $77 \pm 6 \%$, Abreu et al. (2009), com 70 $\pm 8 \%$, e Ascher et al. (2000), com $65,50 \pm 19,3 \%$. Por outro lado, as concentrações espermáticas médias foram inferiores às relatadas por Cheng et al. (2004), com $1.471,3 \pm 940,0 \times 10^{6} / \mathrm{mL}$, Abreu et al. (2009), com $1.536 \pm 351 \times 10^{6} / \mathrm{mL}$, e Ascher et al. (2000), com $2.100 \pm 1.400 \times 10^{6} / \mathrm{mL}$. O vigor espermático observado nos quatro cervos foi superior ao valor

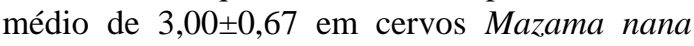
relatado por Abreu et al. (2009). A concentração espermática pode oscilar devido ao método de colheita por eletroejaculação (Chacur, 2012; Chacur et al., 2012) e ao estresse do cativeiro (Ascher et al., 2000; Cheng et al., 2004; Abreu et al., 2009).

A análise histológica dos testículos dos cervos foi realizada, e o material processado pela técnica de hematoxilina-eosina (HE), os quais mostraram integridade do arcabouço dos túbulos seminíferos, observada por meio da presença das células da linhagem espermatogênica dispostas em camadas homogêneas (Fig. 1).

O estudo do perfil proteico do plasma seminal nos animais por meio da eletroforese em SDSPAGE vem sendo correlacionado com a fertilidade deles e pode contribuir para a compreensão dos efeitos dos fatores do clima e da contenção do cativeiro sobre as características reprodutivas (Chacur, 2012).

Com relação ao perfil proteico do plasma seminal dos cervos, os géis revelaram a presença de bandas com pesos moleculares variando entre $7,6 \mathrm{kDa}$ e $142 \mathrm{kDa}$ (Tab. 4). Essas bandas apresentaram diferentes porcentagens de ocorrência, entre $6,66 \%$ e $26,66 \%$ das amostras de plasma seminal. As bandas com ocorrência igual ou superior a $20 \%$ das amostras foram: 10 , $13,19,20,21,29,30,51,82,88,90,96 \mathrm{e}$ $122 \mathrm{kDa}$. Dessas 13 bandas proteicas, sete possuíam pesos moleculares iguais ou inferiores a $30 \mathrm{kDa}$, o que revela uma distribuição homogênea entre a ocorrência de bandas leves (até $50 \mathrm{kDa}$ ) e pesadas (iguais ou superiores a $51 \mathrm{kDa}$ ), conforme ilustrado abaixo (Fig. 2 e Fig. 3).

A banda proteica específica de $13 \mathrm{kDa}$ foi identificada nos animais B, C e D. A proteína de $13 \mathrm{kDa}$, conhecida como PDC-109, confere alta fertilidade em touros, pois age de forma direta no metabolismo dos espermatozoides (Desnoyers, 1994; Roncoletta et al., 1999).

Nos cervos A e B foi observada a banda de 20kDa, a qual, segundo Barrios et al. (2000), pode ser responsável pela recuperação da permeabilidade da membrana espermática após esta ser submetida ao choque térmico pelo frio. 
Morfometria corpórea...

Tabela 4. Ocorrências de bandas proteicas específicas no plasma seminal de cervos Cervus unicolor mantidos em cativeiro

\begin{tabular}{cl}
\hline Cervos & \multicolumn{1}{c}{ Bandas $(\mathrm{kDa})$} \\
\hline $\mathrm{A}$ & 7,6101114151619202127317375818288899697100107120123 \\
$\mathrm{~B}$ & 125129132142 \\
$\mathrm{C}$ & 101318202227303136505152607577818287909295118122131 \\
$\mathrm{D}$ & 101318192129485153798286889296102110119126133142 \\
\hline
\end{tabular}

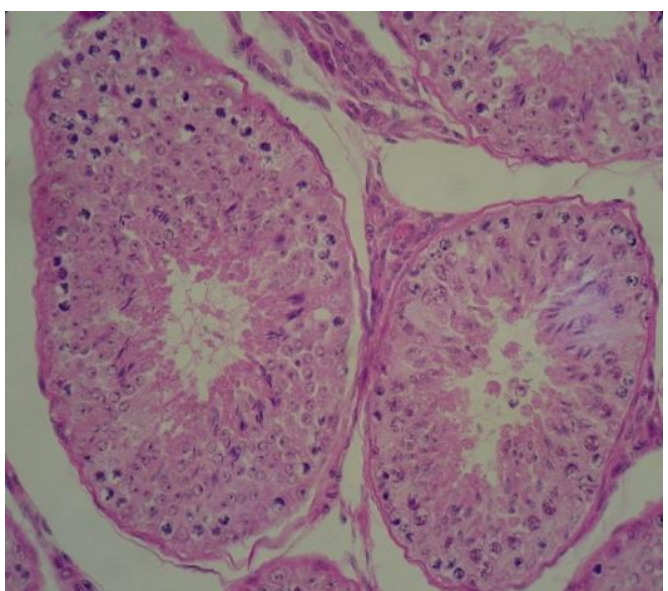

Figura 1. Corte histológico do tecido testicular íntegro, com presença de células da linhagem germinativa (HE, 400x).
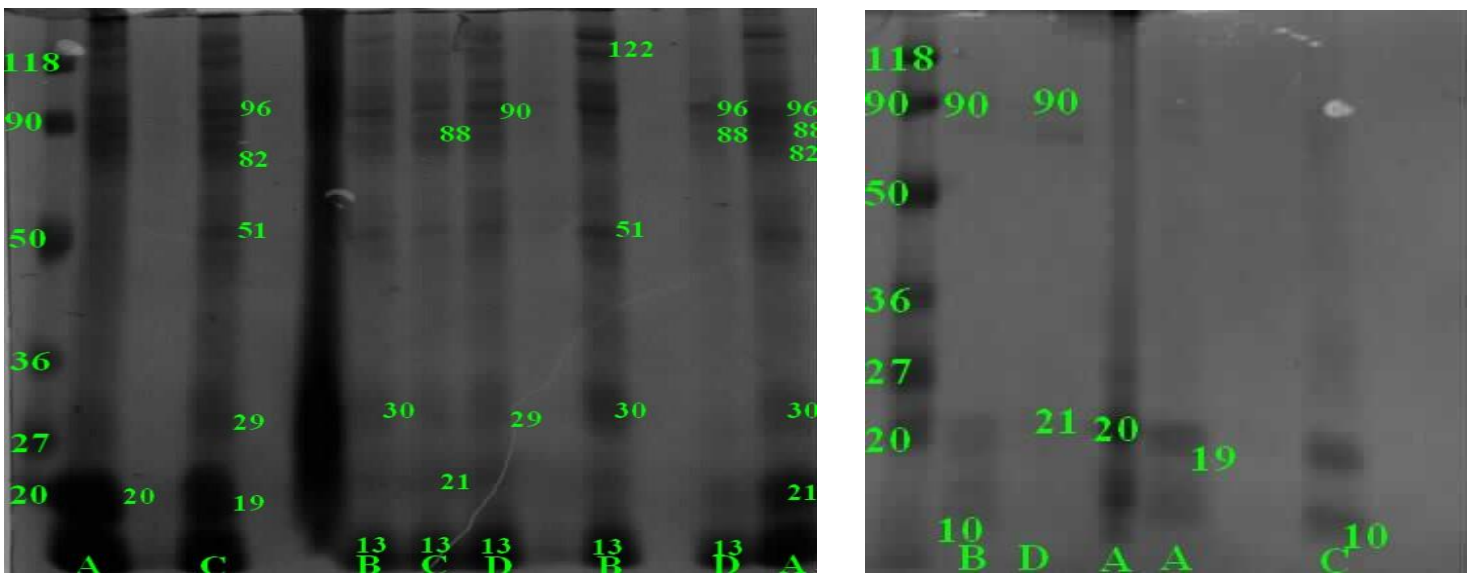

Figuras 2 e 3. Imagens de géis com as bandas proteicas do plasma seminal de cervos Cervus unicolor (letras A, B, C e D). A primeira coluna da esquerda das Fig. 2 e 3 é relativa ao marcador molecular. Os números nas imagens dizem respeito aos pesos moleculares $(\mathrm{kDa})$ das bandas proteicas.

Uma banda proteica de $75 \mathrm{kDa}$ foi encontrada nos cervos A, B e D. Essa proteína é chamada de SP2 , e sua presença é relacionada de forma negativa com a fertilidade (Brandon, 1999).

Proteínas entre 21 e $22 \mathrm{kDa}$ foram identificadas nos cervos A, B, C e D. Proteínas variantes da $\mathrm{HPB}$, com aproximadamente $21,5 \mathrm{kDa}$ e $31 \mathrm{kDa}$, são associadas ao incremento da fertilidade (Bellin et al., 1994). Os animais B e D apresentam a banda de $30 \mathrm{kDa}$. Em bovinos, um grupo de proteínas conhecidas como BSP-A1, BSP-A2, BSP-A3 e BSP-30kDa possivelmente induz alterações moleculares na membrana plasmática, essenciais no processo da capacitação espermática (Bergeron, 2004). 
As bandas de $79 \mathrm{kDa}$ (cervo C); $81 \mathrm{kDa}$ (cervos A e B) e $90 \mathrm{kDa}$ (cervos B e D) foram identificadas. Conforme Chacur et al. (2012), esses peptídeos, quando presentes no plasma seminal, contribuem de forma positiva com as características qualitativas do sêmen em bovinos.

Vale destacar que estudos comprovam a correlação da testosterona com a qualidade espermática de ruminantes criados extensivamente em clima tropical (Chacur et al., 2012). Por outro lado, a literatura consultada traz poucas informações a esse respeito ao tratar dos cervos como objeto de estudo. No presente trabalho, as concentrações séricas de testosterona, obtidas no mês de novembro (primavera), estão descritas na Tab. 5, onde se observam valores maiores para os cervos A e B com idade de 36 meses. Possivelmente, a faixa etária superior dos cervos A e B com 36 meses influenciou na maior concentração de andrógeno circulante. Pesquisas reportaram resultados relativos à concentração de testosterona em cervos de distintas espécies. López et al. (2010) encontraram valores entre 2 e 10ng/dL, também na estação da primavera, em cervos Cervus elaphus hispanicus. Valores similares ao do presente trabalho foram relatados por López et al. em 2010 para a estação do outono com concentração sérica média de $86,5 \pm 16,3 \mathrm{ng} / \mathrm{dL}$. Pereira e Duarte (2005) descrevem concentração de testosterona entre 50 e $100 \mathrm{ng} / \mathrm{dL}$ por meio da colheita de fezes em cervos Ozotoceros bezoarticus bezoarticus.

Tabela 5. Concentração de testosterona sérica (ng/dL) em cervos Cervus unicolor

\begin{tabular}{cc}
\hline Cervo & Testosterona $(\mathrm{ng} / \mathrm{dL})$ \\
\hline A & $166,00 \pm 64,48$ \\
B & $75,86 \pm 15,16$ \\
C & $12,71 \pm 8,51$ \\
D & $6,43 \pm 4,33$ \\
\hline
\end{tabular}

Nas espécies dos cervos, somente os dominantes produzem sêmen de boa qualidade, o que está relacionado com os comportamentos sexual e social a partir do princípio de setembro, época do início da ciclicidade reprodutiva, quando se verifica a presença de fêmeas na fase de estro (Coucelo, 1986). No presente estudo, foi observado comportamento sexual ativo na presença de fêmeas em estro, com cortejo e coberturas, realizados pelos cervos A e B, os quais eram dominantes em relação aos animais $\mathrm{C}$, com idade de 18 meses, e D, com 12 meses.

Correlações significativas têm sido demonstradas entre a concentração sanguínea de testosterona, a fertilidade e a motilidade espermática (Blockey e Galloway, 1978). Uma elevação sazonal da concentração de testosterona foi observada na primavera em cervos Columbian black-tailed, Red deer e Follon deer (West e Nordan, 1976; Rolf e Fischer, 1990). Em cervos White-tailed deer, a máxima concentração de testosterona não foi necessária para $\mathrm{o}$ processo da espermatogênese, mas foi essencial para a manifestação do comportamento reprodutivo (Bubenik et al., 1982).

Segundo Pereira e Duarte (2005), existe correlação significativa entre concentrações de testosterona e comportamento reprodutivo, razão pela qual o ciclo sazonal desse hormônio modula o comportamento sexual dos machos durante o período de acasalamento, quando somente indivíduos com os chifres expostos demarcam o seu território.

\section{CONCLUSÕES}

Qualidade espermática satisfatória foi observada na estação reprodutiva da primavera. As características dos ejaculados não diferiram entre as colheitas sucessivas, exceto a morfologia espermática, que se elevou na quarta colheita, possivelmente devido ao estresse das contenções semanais sucessivas. Grande variedade na distribuição de bandas proteicas no plasma seminal foi obtida, entre 7,6 e 142kDa, o que revela diversas proteínas. A idade influi na concentração sérica de testosterona, a qual foi maior nos cervos com 36 meses.

\section{AGRADECIMENTOS}

Ao Conselho Nacional de Desenvolvimento Científico e Tecnológico ( $\mathrm{CNPq}$ ), Unoeste e Unesp, pelas bolsas concedidas e pelo apoio logístico. 


\section{REFERÊNCIAS}

ABREU, O.C.; MARTINEZ, C.A.; MORAES. W. et al. Características reprodutivas de veadobororó-do-sul ou veado-mão-curta (Mazama nana). Pesq. Vet. Bras., v.29, p.993-998, 2009.

ASCHER, G.W.; BERG, D.K.; EVANS, G. Storage of semen and artificial insemination in deer. Anim. Reprod. Sci., v.62, p.195-211, 2000.

BARRIOS, B.R.; PÉREZ-PÉ, M.; GALEGO, A. et al. Seminal plasma protein reverse the coldshock damage of ram sperm membrane. Biol. Reprod., v.63, p.1531-1537, 2000.

BELLIN, M.E.; HAWKINS, H.E.; AX, R.L. Fertility of ranger beef bulls grouped according to presence or absence of heparin binding protein in sperm membranes and seminal fluid. J. Anim. Sci., v.72, p.2441-2448, 1994.

BERGERON, A. Comparative study on the phospholipid-binding proteins in seminal plasma of different species. In: INTERNATIONAL CONGRESS ON ANIMAL REPRODUCTION, 15., 2004, Porto Seguro. Proceedings...Porto Seguro: International Embryo Transfer Society. [n.1] 2004. p.226. (Abstract).

BLOCKEY, M.A.; GALLOWAY, D.B. Hormonal control of serving capacity in bulls. Theriogenology, v.9, p.143-151, 1978.

BRADFORD, M.M. A rapid and sensitive method for the quantification of microgram quantities of protein utilizing the principle of protein-dye binding. Analytical Biochem., v.72, p.248-254, 1976.

BRANDON, C.I. The cause of pathologic changes of testicular degeneration in large animals. Vet. Med., v.23, p.531-536, 1999.

BUBENIK, G.A.; MORRIS, J.M.; SCHAMS, D.; CLAUS, A. Photoperiodicity and circannual levels of LH, FSH, and testosterone in normal and castrated male, white-tailed deer. Can. J. Physiol. Pharmacol., v.60, p.788-793, 1982.

CHACUR, M.G.M. Seminal Plasma Proteins as Potential Markers of Relative Fertility in Zebu Bulls (Bos taurus indicus), In: GHOWSI, K. (Ed). Electrophoresis. Croatia: IN TECH, 2012. p. $1-20$.
CHACUR, M.G.M.; AURÉLIO, P.T.F.; OBA, E. et al. Influência de um nutracêutico no sêmen, testosterona, cortisol, eritrograma e peso corpóreo em touros jovens Bos taurus indicus. Sem. Agrárias, v.31, p.439-450, 2010.

CHACUR, M.G.M.; MIZUSAKI, K.T.; SANTOS F.H. et al. Influência da estação do ano nas características do sêmen e na concentração de hormônios em touros Nelore e Simental. Arq. Bras. Med. Vet. Zootec., v.64, p.540-546, 2012.

CHENG, F.P.; WU, J.; CHAN, J. et al. The effect of different extenders on post-thaw sperm survival, acrosomal integrity and longevity in cryopreserved semen of Formosan Silka deer and Formosan Samba deer. Theriogenology, v.61, p.1605-1616, 2004.

COUCELO, M. Bases biológicas essenciais para o ordenamento do veado. 1.ed. Porto: Lisboa, 1986. 64p.

DESNOYERS, L. Characterization of the major proteins of bovine seminal fluid by two dimensional polyacrilamide gel electrophoresis. Molec. Reprod. Develop., v.37, p.425-443, 1994.

DUARTE, J.M.B.; MERINO, M.L. Tecnologia da reprodução para a propagação e conservação de espécies ameaçadas de extinção, In: DUARTE, J.M.B. (Ed). Biologia e conservação de cervídeos sul-americanos: Blastocerus, Ozotoceros e Mazama. Brasil: FUNEP. 1997. p.228-238.

EINSPANIER, R. Characterization of a new bioactive protein from bovine seminal fluid. Biochem. Biophys. Res. Communications, v.179, p.1006-1010, 1991.

GASSET, M. Conformation features and thermal stability of bovine seminal plasma protein PDC109 oligomers and phosphorylcholine-bind complexes. Eur. J. Biochem., v.250, p.735-744, 1997.

LAEMMLI, U.K. Cleavage of structural proteins during the assembly of the head of bacteriophage T4. Nature, v.227, p.680-685, 1970.

LÓPEZ, G.E.; CASTILlEJOS, L.T.; CEACERO, F. et al. Testosterone, Cortisol and Antler Growth Cicle in Iberian Red Deer Stags (Cervus elaphus hispanicus). Reprod. Dom. Anim., v.45, p.243249, 2010. 
MANJUNATH, P. Purification and biochemical characterization of three major acidic proteins (BSP-A1, BSP-A2 and BSP-A3) from bovine seminal plasma. Eur. J. Biochem., v.241, p.685$692,1987$.

PEREIRA, G.J.R.; DUARTE, B.M.J. Seasonal changes in fecal testosterone concentrations and their relationship to the reproductive behavior, antler cycle and grouping patterns in free-ranging male Pampas deer (Ozotoceros bezoarticus bezoarticus). Theriogenology, v.63, p.21132125, 2005

POCAY, P.L.B.; POCAY, V.G.; STARLING, J.M.C. et al. Respostas fisiológicas de vacas holandesas predominantemente brancas e predominantemente negras sob radiação solar direta. ARS Veterinária, v.17, p.155-161, 2001.

ROLF, H.J.; FISCHER, K. Serum testosterone (T) and 5- $\alpha$-dihydrotestosterone (DHT) in male fallow deer (Dama dama L.): Seasonality and age dependence. Comparative Biochemistry and Physiology Part A. Physiol., v.95A, p.445-452, 1990.

RONCOLETTA, M.; FRANCESCHINI, P.H.; LIMA, V.F.M.H. et al. Perfil em SDS-PAGE das proteínas do plasma seminal e sua relação com a congelabilidade do sêmen de touros doadores da raça Gir. Braz. J. Vet. Res. Anim. Sci., v.36, p.143-148, 1999.
SALVADOR, D.F.; DIAS, J.C.; VALE FILHO, V.R. et al. Perfil andrológico de touros da raça Nelore com três e quatro anos de idade, criados extensivamente em condições do estado do Mato Grosso do Sul. Rev. Bras. Reprod. Anim., v.26, p.64-67, 2002.

VALE FILHO, V.R.; PINHEIRO, L.E.L.; BASUR, P.K. Reproduction in zebu cattle. In: MORROW, D.A. (Ed). Current therapy in theriogenology. W.B. Saunders: New York, 1986, p.437-442.

VAN SOEST, P.J. Nutritional ecology of the ruminant. 1.ed Ames: Cornell University, 1994. 476p.

WEST, N.O.; NORDAN, H.C. Hormonal regulation of reproduction and the antler cycle in the male Columbian black-tailed deer (Odocoileus hemionus columbianus). Part I. Seasonal changes in the histology of the reproductive organs, serum testosterone, sperm production and the antler cycle. Can. J. Zool., v.54, p.1617-1636, 1976. 